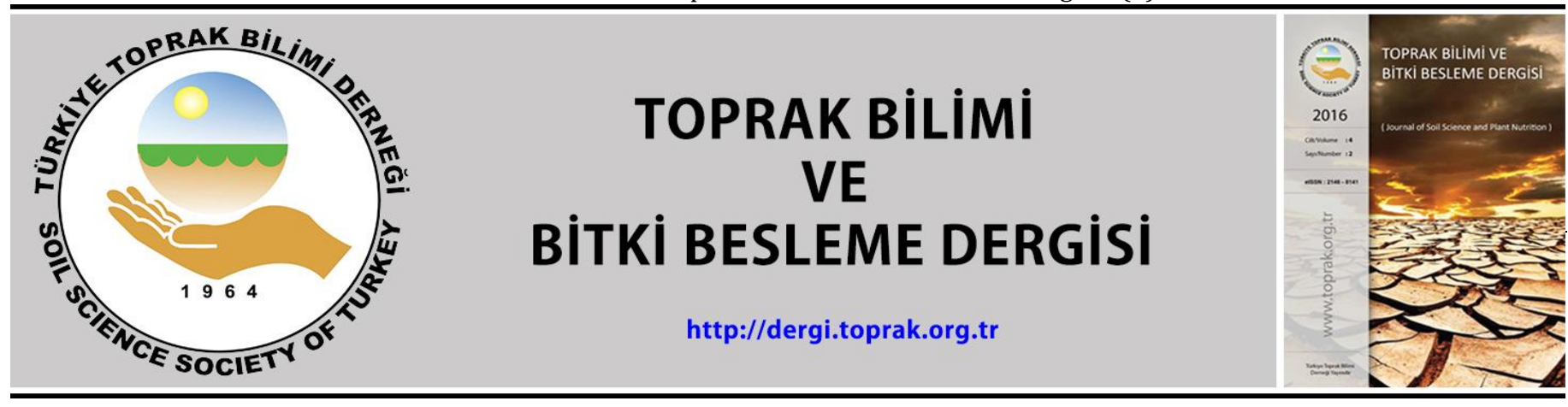

\title{
Trakya topraklarının veri tabanının olușturulması ve bazı toprak özellikleri
}

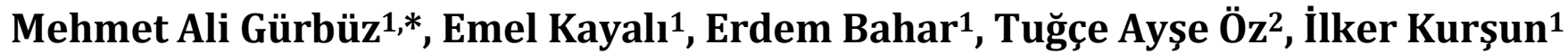 \\ ${ }^{1}$ Atatürk Toprak Su ve Tarımsal Meteoroloji Araştırma Enstitüsü Müdürlüğü, Kırklareli \\ ${ }^{2}$ Toprak, Gübre ve Su Kaynakları Merkez Araştırma Enstitüsü Müdürlüğü, Ankara
}

\begin{abstract}
Özet
Bu çalıșmada, Trakya'nın büyük bir kısmını oluşturan (İstanbul ve Gelibolu Yarımadası hariç) Kırklareli, Edirne ve Tekirdağ illerinde bulunan tarım arazilerinin, toprakların bitki besin maddesi ve verimlilik durumu ile potansiyel toksik element kapsamlarının belirlenmesi, belirlenen bu toprak özelliklerinin Coğrafi Bilgi Sistemleri (CBS) kapsamında değerlendirilerek toprak veri tabanları oluşturulması ve haritalanması amaçlanmıştır. Bu amaçla, 2014-2015-2016 yıllarında tarım arazilerinden 0-20 cm toprak derinliğinden 2,5 kmx2,5 km grid sistemine göre toprak örnekleri alınmıştır. Alınan bu toprak örneklerinde, temel verimlilik parametreleri (bünye, suyla doygunluk, toprak reaksiyonu, elektriksel iletkenlik, kireç, organik madde, yarayıșlı fosfor), makro ve mikro besin elementleri (ekstrakte edilebilir $\mathrm{K}, \mathrm{Ca}, \mathrm{Mg}, \mathrm{Na}, \mathrm{B}, \mathrm{Fe}, \mathrm{Cu}, \mathrm{Zn}, \mathrm{Mn}$ ) ve potansiyel toksik element içerikleri (Cu, Zn, $\mathrm{Ni}, \mathrm{Cd}$, $\mathrm{Cr}, \mathrm{Pb}$ ve $\mathrm{Co}$ ) belirlenmiştir. Trakya topraklarının bu araştırma kapsamında yapılan analiz sonuçları değerlendirildiğinde, bünye bakımından toprakların yaklaşık, $1 / 3$ 'ü hafif, $1 / 5$ 'i orta ve $2 / 5$ 'i ağır bünyeli olduğu söylenebilir. Toprak reaksiyonu bakımından, yaklaşık 2/5'i asit, 1/5'i nötr ve 2/5'i alkalin reaksiyonlu, tuz bakımından 3/4'ü tuzsuz ve diğer kısmı çok hafif ve hafif tuzlu, kireç bakımından 1/2'si kireçsiz ve çok az kireçli, $1 / 7$ az kireçli, $1 / 5$ 'i orta kireçli ve kireçli ve $1 / 10^{\prime}$ 'u ise çok kireçli sayılabilir. Organik madde bakımından $1 / 5^{\prime} \mathrm{i}$ çok az, 3/5'i az, 1/5'i ise orta ve zengin, fosfor bakımından 1/5'i yetersiz ve çok yetersiz, 1/4'ü orta, 3/10'u yüksek ve $1 / 5^{\prime}$ i çok yüksek, ekstrakte edilebilir potasyum bakımından, $1 / 7$ 'si az, 1/4'ü orta ve yeterli, 3/5'i yüksek ve çok yüksek sınıfında yer almıştır. Ekstrakte edilebilir magnezyum bakımından 1/10'u yetersiz ve çok yetersiz, 3/5'i orta ve 1/5'i ise yüksek ve çok yüksek, ekstrakte edilebilir demir bakımından ise yaklaşık 1/10 az, kalan kısmı ise yeterli sınıfında yer almıştır.
\end{abstract}

Anahtar Kelimeler: Trakya, toprak özellikleri, veri tabanı.

\section{Composing the database of thrace soils and some soil characteristics}

\begin{abstract}
In this study, determining the nutrients of the soils, productivity and potential toxic elements, composing the soil data base and mapping of the agricultural lands by evaluating the characteristics within Geographic Information Systems (GIS) in Kurklareli, Edirne and Tekirdağ provinces which compose a major part of Thrace region (except İstanbul and Gallipoli) was aimed. For this purpose, soil samples were obtained according to $2.5 \mathrm{~km}$ x $2.5 \mathrm{~km}$ grid system from $0-20 \mathrm{~cm}$ surface from the agricultural lands in 2014-2015-2016 years. In these soil samples, main soil fertility parameters (texture, saturation percentage, soil reaction, electrical conductivity, lime content, organic matter content, available phosphorus), macro and micro nutrients (exchangeable $\mathrm{K}, \mathrm{Ca}$, $\mathrm{Mg}, \mathrm{Na}$ and $\mathrm{B}$, plant-available $\mathrm{Fe}, \mathrm{Cu}, \mathrm{Zn}$ and $\mathrm{Mn}$ ) and potential toxic element contents $(\mathrm{Cu}, \mathrm{Zn}, \mathrm{Ni}, \mathrm{Cd}, \mathrm{Cr}, \mathrm{Pb}$ and $\mathrm{Co})$ were determined. When the results of the analysis of Thrace soils are evaluated within the scope of this research, it can be said that about $1 / 3$ of the land is light, $1 / 5$ is medium and $2 / 5$ is heavy. For soil reaction, approximately $2 / 5$ of the acid, $1 / 5$ of the neutral and $2 / 5$ of the alkaline reaction. $3 / 4$ of soil is salt free and the other part is very light and slightly salty. In terms of lime, $1 / 2$ is not calcareous and very little calcareous, $1 / 7$ is little calcareous, $1 / 5$ is medium calcareous and calcerous and $1 / 10$ is very high calcareous. In terms of organic matter, $1 / 5$ is very poor, $3 / 5$ is less, $1 / 5$ is medium and rich, $1 / 5$ of phosphorus is inadequate and very inadequate, $1 / 4$ is medium, $3 / 10$ of them are high and $1 / 5$ is very high, $1 / 7$ of potassium is inadequate, $1 / 4$ is middle and rich and $3 / 5$ is rich and very rich. In terms of extractable magnesium, $1 / 10$ is inadequate and very inadequate, $3 / 5$ is medium and $1 / 5$ is high and very high, extractable iron is /10 low and the rest is in sufficient class.
\end{abstract}

Keywords: Thrace, soil characteristics, database.

* Sorumlu yazar:

Tel. : : $\quad 02882144885$

E-posta : gurbuzmehmetali@tarim.gov.tr
Geliş Tarihi Kabul Tarihi
20 Ekim 2017

09 Şubat 2019
e-ISSN

DOI
$2146-8141$

$10.33409 /$ tbbbd. 595133 


\section{Giriş}

Doğal faktörlerin etkisiyle binlerce yılda oluşan toprağın özellikleri, insanlar tarafından tarımsal üretim amacıyla kullanılmaya başladıktan sonra hızla değişmektedir. Bu değişim; çoğunlukla verim gücünün azalmasına, erozyon ve diğer kullanımlarla kaybedilmesi yönünde olmaktadır. Toprakların doğal oluşum özelliklerine uygun olarak kullanılabilmesi için, bilim insanları tarafından etüdü, haritalanması ve sınıflaması yapılmaktadır. Ülkemizde bu tür çalışmalar Mülga Toprak-Su Genel Müdürlügü tarafından önce havza bazında, daha sonra il arazi varlıkları ve toprak özelliklerini de o zamanın sınıflama sistemi ile rapor halinde yayınlanmıştır. Ancak, hazırlanan bu raporlar pratiğe aktarılamamış ve topraklarımızın idaresi Arazi Kullanım Kabiliyet Sınıflarına (AKK) uygun olarak yapılamamıştır. Bu durumda ülke tarım topraklarının bir kısmının sanayi ve kentleşme amacıyla kullanılmasına, doğal niteliğine uygun kullanılmadığı için erozyonla kaybedilmesine, aşırı toprak işleme ve sulama nedeniyle sömürülerek fakirleșmesine ve üretkenliğinin azalmasina neden olmuştur.

Trakya yöremiz, ülkemizin kuzey batısında bulunan Marmara bölgemizin Avrupa kesiminde yer almakta, 2.372.100 ha alanı kaplamakta ve ülke yüzölçümünün \%3,1'ini oluşturmaktadır. Trakya'nın batısında Meriç Nehri Yunanistan sınırını oluşturmakta, kuzeyinde Bulgaristan ve Karadeniz, güneyinde ise Marmara Denizi yer almaktadır. Trakya'nın yaklaşık \% 63'ü Meriç, \%37'si ise Marmara Havzasında yer almaktadır. Trakya kesimi fizyografik olarak dalgalı (peneplen) yapıya sahiptir. En yüksek nokta Trakya'nın kuzey kısmında yer alan Istranca Dağlarındaki Mahya Tepesi (1031 m)'dir. Trakya'nın ortalama yüksekliği $180 \mathrm{~m}$. dir. Trakya'nın orta kesiminde Ergene Nehri ve havzası adeta bir ana drenaj kanalı gibi havzanın kuzey, batı ve güneyinden toplanan akarsuların birleşmesi ile oluşur ve Meriç Nehri ile birleşerek Ege Denizine dökülür.

Trakya jeolojik olarak volkanik, tortul ve metamorfik kütleleri dağınık şekilde içermekte ve Balkan Yarımadasının devamı şeklinde yer almaktadır. Dolayısıyla farklı ana materyallerden toprak oluşumlarının gerçekleştiği bir bölge olmaktadır. Bu durum toprakların özelliklerine de yansımakta ve idarelerini güçleştirmektedir. Bölge, iklim olarak ise, yazları sıcak ve kurak, kışları ise serin ve yağışlıdır. Trakya'nın orta kesimi en kurak kısmı olup burada yağış 560 mm civarında iken, Karadeniz'e yakın olan kuzey-batı kısımlarda 800-1000 mm'ye ulaşmaktadır.

Ülkemizde kimyevi gübrelerin tarımsal üretimde kullanımının yaygınlaşması çok eski değildir. Yaklaşık yarım asırdır bu alanda gitgide artan bir üretim ve kullanım durumu söz konusudur. Bu konuda da Mülga TOPRAKSU Genel Müdürlügü tarafından her ilimizin verimlilik envanteri ve gübre ihtiyaç raporu hazırlanmıştır. Bu raporlarda, illerimizin temel topraklarının büyük toprak grupları, toprak bünyesi (ișba'dan), pH, kireç, organik madde, alınabilir fosfor ve ekstrakte edilebilir potasyum miktarları belirlenmiş, 1/25.000 ölçekli haritalarda büyük toprak grupları ve toprak reaksiyonu gösterilmiştir. $\mathrm{Bu}$ analiz sonuçlarına göre, her ilin ilçe düzeyinde arazi büyüklügü, ekilen tarımsal ürünün oranı göz önüne alınarak kullanılması gereken azotlu, fosforlu, potasyumlu gübre miktarları hesaplanmıştır. İl'de şayet asit topraklar mevcut ise, kullanılması gereken kireç ihtiyacı miktarı da hesaplanmıştır. (Toprak su, Tekirdağ, Kırklareli, Edirne 1984).

Eyüpoğlu ve ark. (1998), Türkiye topraklarının bitkiye yarayışlı bazı mikro elementler (Fe, $\mathrm{Cu}, \mathrm{Zn}, \mathrm{Mn}$ ) bakımından genel durumunu belirlemek amacıyla yürüttükleri çalışmalarında; ülke topraklarını temsilen alınan 1511 adet toprak örneğinin analizi sonucunda, Türkiye topraklarının \% 49.83'ünde Zn, \% 26.87'sinde $\mathrm{Fe}, \%$ 0.70'inde Mn eksikliğinin söz konusu olduğu, topraklarda bakırla ilgili olarak bir eksiklik sorununun olmadığı belirlenmiştir.

Taşova ve Akın (2013), tarafından yapılan bir çalışmada, Marmara Bölgesi topraklarının bitki besin maddesi kapsamlarının belirlenmesi ve veri tabanının oluşturulması hedeflenmiştir. Bu çalışmada mikro besin elementlerinden $\mathrm{Fe}, \mathrm{Cu}, \mathrm{Zn}$ ve Mn miktarları da DTPA yöntemine göre belirlenmiştir. Mikro besin elementleri bakımından Marmara Bölgesi topraklarının \%86,7 Fe bakımından yeterli, \% 99,4 Cu bakımından yeterli, \%54,4'ü Zn bakımından az-çok az ve Mn bakımından ise \% 60,1'i az ve çok az, \% 39,9'u ise yeterli bulunmuştur.

Geçen yüzyılda yapılmış çalışmalardan sonra il veya bölgesel düzeyde Trakya'nın toprak özelliklerinin belirlenmesi ve veri tabanının oluşturulması konusunda ayrıntılı bir çalışmaya rastlanmamaktadır. Bu çalışma, ülkesel Toprak Veritabanının oluşturulması çalışmasının Trakya kısmını yürüten ekip tarafından 2014-2017 yılları arasında Tekirdağ, Edirne ve Kırklareli illerini kapsayacak şekilde yürütülmüştür.

\section{Materyal ve Yöntem}

Bu çalışmada, arazisinin tamamı Trakya'da olan ve Trakya'nın büyük kısmını oluşturan Tekirdağ, Kırklareli ve Edirne ili tarım arazilerinden toprak örnekleri alınmıştır. Bu amaçla, 2014-2015-2016 yıllarında, tarım 
alanlarından, 0-20 cm yüzeyden $2.5 \mathrm{~km}$ x $2.5 \mathrm{~km}$ grid sistemine göre, toprak örneklemesi yapılmış ve bu üç ilden toplam 1912 adet örnek alınmıştır. Trakya Yöresi tarım arazilerinden toprak örneği alınan noktalar Şekil 1'de gösterilmiştir. Bu örneklerde yapılan analizlerine ilişkin yöntemler aşağıda verilmiştir.

Bünye, Bouyoucus hidrometre metoduna göre belirlenmiştir (Bouyoucos, 1951). Toprak reaksiyonu (pH), hazırlanan saturasyon çamurunda cam elektrotlu $\mathrm{pH}$ metreyle, kireç $\left(\mathrm{CaCO}_{3}\right)$ Scheibler kalsimetresinde volümetrik olarak, organik madde Modifiye edilmiş Walkley-Black yöntemiyle, ekstrakte edilebilir potasyum ve magnezyum, $1 \mathrm{~N}$ Amonyum Asetat ( $\mathrm{pH}=7.0)$ çözeltisi ile ekstrakte edilerek ICP-OES cihazında, toprakların yarayışlı fosfor içerikleri Olsen yöntemiyle Methods of Soil Analysis (1982)'de bildirildiği şekilde belirlenmiştir. Elektriksel iletkenlik (EC) (dS/m): Toprakların toplam tuz içerikleri, saturasyon çamurundan çıkartılan ekstraktta kondaktivite cihazı ile ölçülecektir (Richards, 1954). Ekstrakte edilebilir demir (Fe): DTPA ile ekstrakte edilerek radyal plazma İCP-OES cihazında belirlenmiştir (Lindsay ve Norvel, 1978).

Toprak Haritalarının Oluşturulması: Koordinatlı olarak alınan toprak örneklerine ait toprak analiz sonuçlarını içeren veriler ayrı ayrı ele alınarak CBS' nin analiz fonksiyonlarından yararlanılarak değerlendirilmiştir. Koordinatlı olarak alınan toprak örneklerine ilişkin parametrelere ait haritaların çiziminde ArcMap10.4 coğrafi bilgi sistemleri paket programı kullanılmıştır. Jeoistatistik yöntem olarak "ordinary kriging" yöntemi tercih edilmiştir.

Marmara Bölgesi Trakya bölmümünün arazi örtüsü ve arazi kullanım türlerinin belirlenmesinde Avrupa Birliği ülkeleri tarafından 1985 geliştirilmiş olan Çevre Bilgileri Koordinasyonu (Coordination of Information on the Environment, CORINE) programı kullanılmıștır. Avrupa ülkelerinin ve Türkiye topraklarının tümünün içine dâhil olduğu arazi kullanım türleri 1990, 2000, 2006 ve 2012 yılları için hazırlanmıştır. Şekil 2'de CORINE 2012'ye ait ana arazi kullanım türleri görülmektedir (Bahar, 2014)

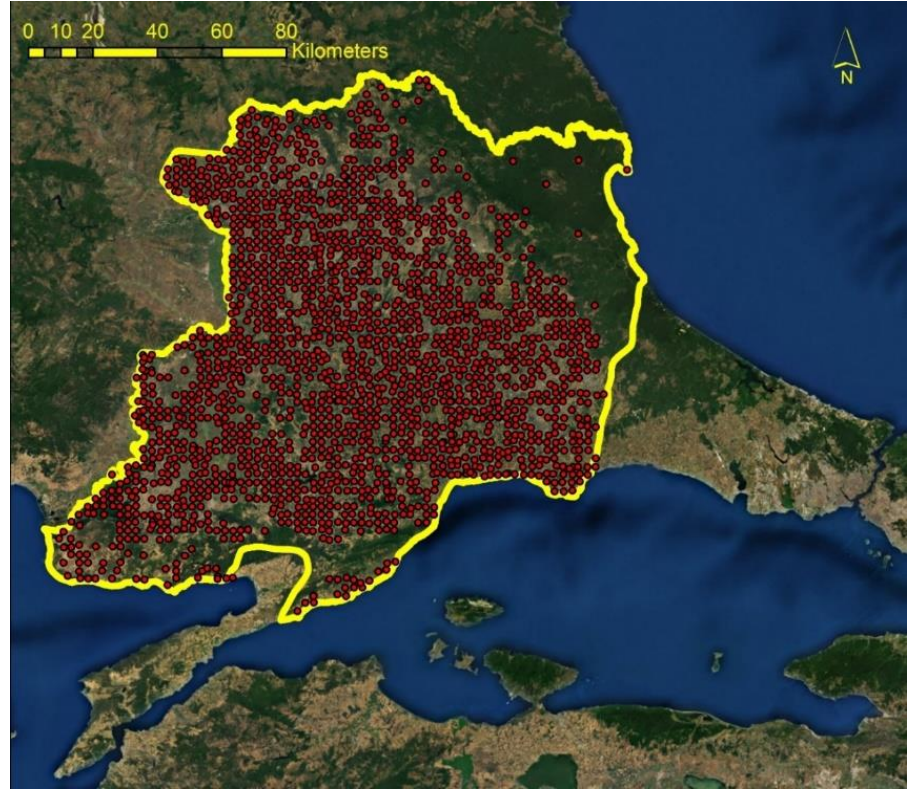

Şekil 1. Trakya Yöresi tarıma arazilerinden toprak örneği alınan noktalar

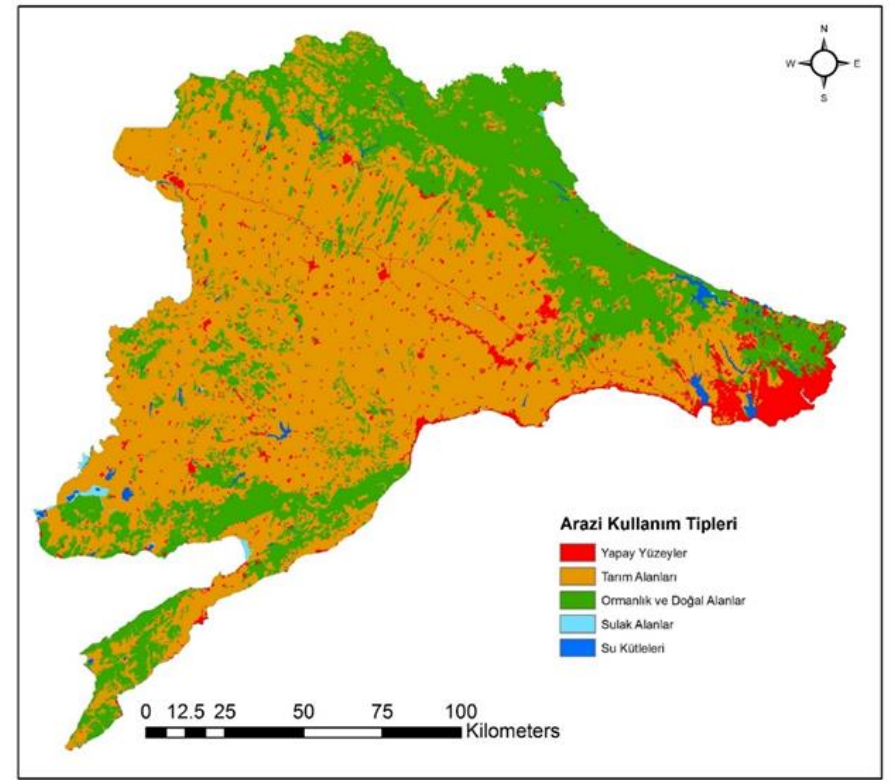

Şekil 1. Marmara Bölgesi Trakya bölümü topraklarının arazi kullanım grupları (CORINE 2012'den uyarlanmıştır)

\section{Bulgular ve Tartışma}

\section{Trakya Topraklarının Bünye Durumu}

Trakya tarım arazilerinden alınan toprak örneklerinin bünye durumu Çizelge 1'de ve bu toprakların bünye sınıflarına göre \% dağılımını gösteren grafik Şekil 3'de verilmiştir.

Çizelge 1. Trakya topraklarının bünye sınıflarına göre dă̆glımı

\begin{tabular}{llllcc}
\hline & Bünye sembolü & Bünye sınıfları & İsmi & Örnek SayıSı & Dağılımı (\%) \\
\hline \multirow{2}{*}{ Bünye } & S, LS & Çok kaba bünyeli & Kumlu, tınlı kum & 59 & 3 \\
& SL, SCL & Hafif kaba bünyeli & Kumlu tın, kumlu killi tın & 641 & 33 \\
& SiL, SiCL & Orta-hafif bünyeli & Siltli tın, siltli killi tın & 451 & 23 \\
& CL, L & Orta-ağır bünyeli & Killi tın, tın & 532 & 35 \\
\\
Si, SC & Biraz ağır bünyeli & Siltli, kumlu kil & 194 & 2 \\
SiC, C & Ağır bünyeli & Siltli kil, kil & 10 \\
\hline
\end{tabular}




\section{Trakya Toprakları Bünye Dağılımı (\%)}

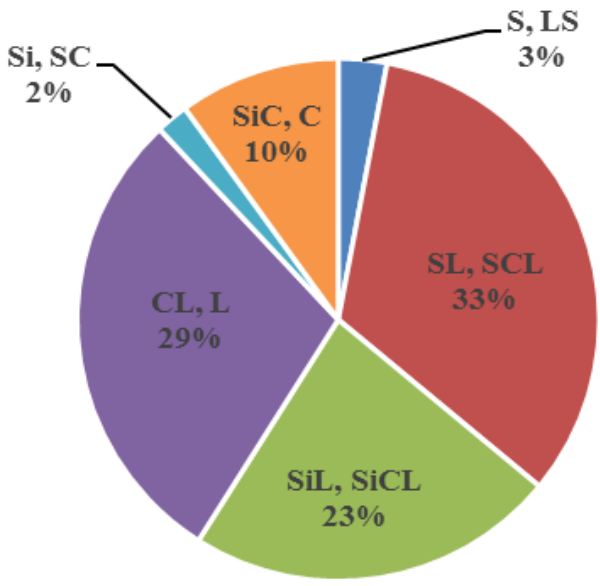

Çizelge 1 ve Şekil 3'deki Trakya tarım arazilerini oluşturan toprakların bünye durumu incelendiğinde, 1/3'ünün kaba bünyeli, kumlu ve kumlu tın topraklardan, 1/5'inin orta bünyeli diyebileceğimiz siltli tın ve siltli killi tın ve kalan kısmının $\left(2 / 5^{\prime} \mathrm{i}\right)$ ise, orta-ağır ve ağır bünyeli topraklardan oluştuğu görülmektedir. Trakya'da alüviyal topraklardan oluşan arazilerin geniş alanlar kaplamadığı bilinmektedir. Bu yüzden, kaba bünyeli topraklar volkanik ana materyalden, ağır bünyeli toprakların ise sedimenter kökenli marn ana materyalinden oluştuğu söylenebilir.

Şekil 3. Trakya topraklarının bünye dağılımı

\section{Trakya Topraklarının Toprak Reaksiyonu (pH) Durumu}

Trakya topraklarının toprak reaksiyonunu sinıflaması ve dağılımı Çizelge 2'de, arazilerinin tamamı Trakya Yöresinde bulunan Edirne, Kırklareli ve Tekirdağ illerinin tarım alanlarının toprak reaksiyonu dağılımı Şekil 4'de görülmektedir. Çizelge 2 ve Şekil 4'deki Trakya topraklarının, toprak reaksiyonu verilerini değerlendirdiğimizde, \%13'unun kuvvetli asit, \% 15 'inin orta asit ve \%10 hafif asit reaksiyonda eklendiğinde asit toprakların oranı toplam \%35'e ulaşmaktadır. Şekil 4'teki haritayı incelediğimizde her üç ilimizin de, kuzey kısımlarında asit reaksiyonlu topraklar bulunmaktadır. $\mathrm{Bu}$ topraklardaki asit reaksiyonun temel nedeninin volkanik ana materyal kaynaklı olduğu bilinmekle birlikte, yörede yaygın olarak kullanılan fizyolojik asit karakterli üre-amonyum azotu içerikli gübrelerin asitliğin artmasında etkili olduğu düşünülmektedir. Çünkü özellikle bu tür gübreler nitrifiye olduklarında hidrojen açığa çıkmaktadır. Şayet toprak reaksiyonu nötr ve hafif asit reaksiyonlu ise her yll mineral azotlu gübre

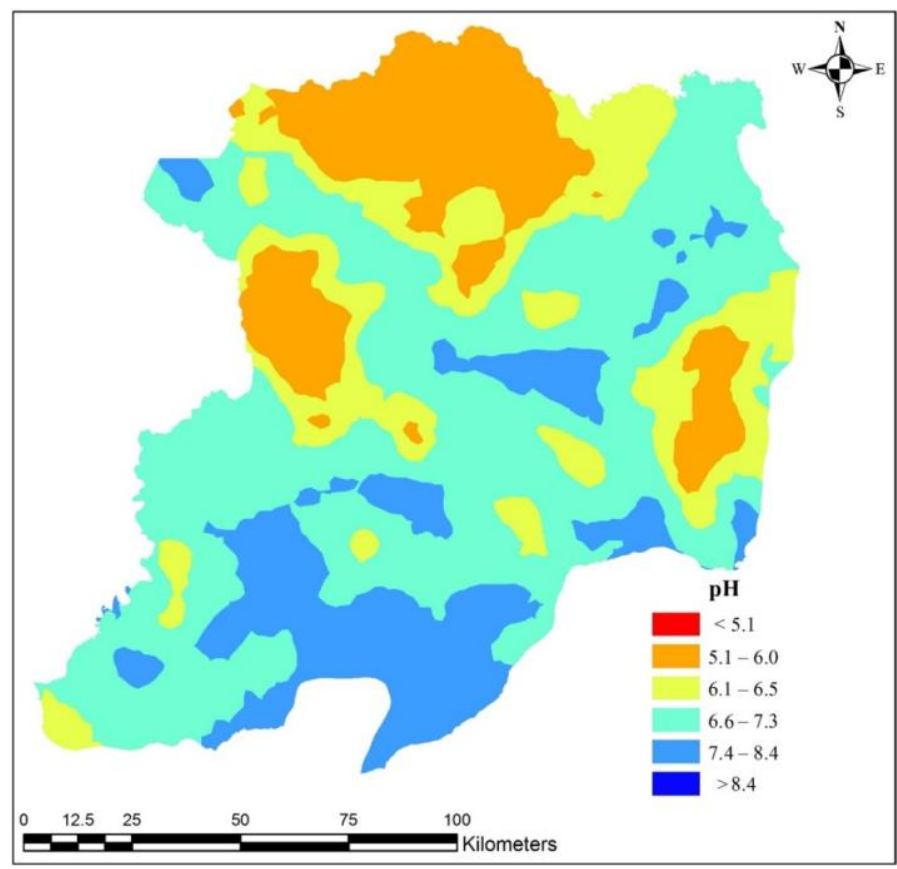

Şekil 4.Trakya topraklarının toprak reaksiyonu (pH) haritası kullanımı ve kireçleme yapılmadığı zaman toprak iyice asitleşmektedir.

Çizelge 2. Trakya topraklarının toprak reaksiyonu (pH) dağılımı

\begin{tabular}{lllcc}
\hline & Değeri & Sınıfi & Örnek Sayısı & Dağılımı (\%) \\
\hline & $<5,10$ & Kuvvetli asit & 255 & 13 \\
& $5,10-6,00$ & Orta asit & 285 & 15 \\
pH & $6,11-6,50$ & Hafif asit & 187 & 10 \\
& $6,51-7,30$ & Nötr & 393 & 21 \\
& $7,31-8,40$ & Orta alkalin & 792 & 41 \\
& $>8,41$ & Kuvvetli alkalin & 0 & 0 \\
\hline
\end{tabular}




\section{Trakya Topraklarının Tuzluluk (EC) Durumu}

Çizelge 3 ve Şekil 5 'teki Trakya topraklarının tuz dağılımı incelendiğinde, 2/3'ünün tuzsuz, 1/5'inin çok hafif tuzlu ve kalan çok az bir kısmının da hafif ve orta kuvvetli tuzlu olduğu görülmektedir. Trakya'da ki tarım arazilerinde tuz sorununun çok az olacağı açıktır. Tuz miktarının bu kadar düşük olmasının pek çok nedeni olabilir; bunlar toprak ana materyalinin büyük kısmının asit reaksiyonlu oluşu, yarı nemli sayılabilecek düzeydeki yağış miktarı ve kapalı tarım havzası bulunmaması, peneplen fizyografyadan dolayı yıkanan tuzların arazide biriktirilmeyip akarsularla denizlere taşınması sayılabilir. Trakya'nın Yunanistan'a yakın İpsala Ovasında, Edirne ilimizde yer alan az miktardaki hafif tuzlu toprakların bulunmasının nedeni, Ergene nehrinin İpsala dolayında getirdiği alüviyonları bırakması ve burada oluşan ovada çeltik tarımının yapılması, deniz seviyesine yakınlık sayılabilir.

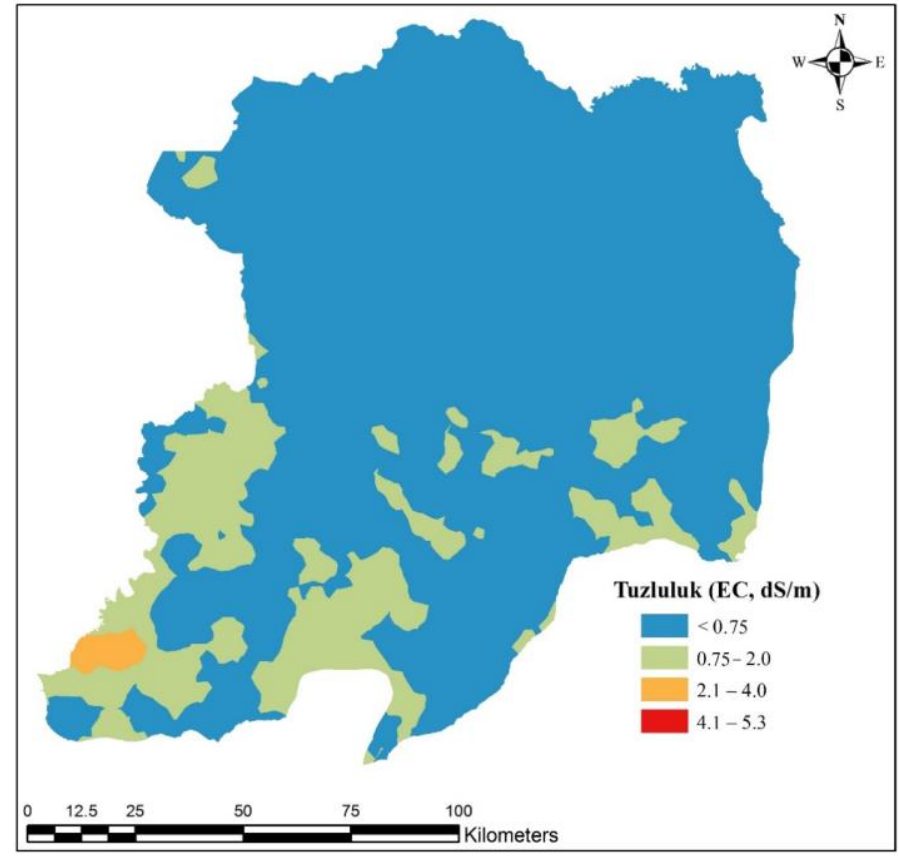

Şekil 5. Trakya topraklarının tuzluluk (EC) haritası

Çizelge 3. Trakya topraklarının tuzluluk sınıflarına göre dağılımı.

\begin{tabular}{cclcc}
\hline & Değeri & Tuzluluk Sınıfi & Örnek Sayısı & Dă̆ılımı (\%) \\
\hline & $<0,75$ & Tuzsuz & 1469 & 77 \\
& $0,75-2$ & Çok hafif tuzlu & 398 & 21 \\
EC & $2-4$ & Hafif tuzlu & 34 & 2 \\
& $4-8$ & Orta kuvvetli tuzlu & 11 & 0 \\
& $8-16$ & Kuvvetli tuzlu & 0 & 0 \\
& $>16$ & Aşırı tuzlu & 0 & 0 \\
\hline
\end{tabular}

\section{Trakya Topraklarının Kireç Durumu}

Çizelge 4 ve Şekil 6'daki Trakya topraklarının kireç dağılımı incelendiğinde, yarıdan fazlasının kireçsiz, $1 / 4$ 'ünün az ve orta kireçli, 1/10'unun ise çok kireçli, marn-kireç toprağı olduğu ifade edilebilir. Toprakların kireç durumu birinci derecede ana materyale bağlıdır. Yörede hem volkanik ve hem de sedimenter ana materyal üzerinde toprak oluşumu, farklı kireç içeriğine sahip toprakların oluşmasına neden olmaktadır. Yöre topraklarının yarıdan fazlasının az kireçli ve kireçli olması, ana materyale ve toprakların oluşumunda etkili olan yağış rejimi ile de ilgilidir. Kirecin toprak profilinden uzaklaşarak toprağın asitleşmesi, bu defa çoğu tarım ürününün yetiştirilebilmesi için, kireçlemenin yapılmasını gerektirmekte, bu durum da tarımsal üretimde ilave masrafa ihtiyaç göstermektedir. Yörede, az miktarda bulunan fazla kireçli topraklarda ise, bitki beslenmesinde özellikle fosfor ve mikrobesin elementi sorunları ortaya çıkmaktadır. Bu durumda yaprak gübrelemesi gibi

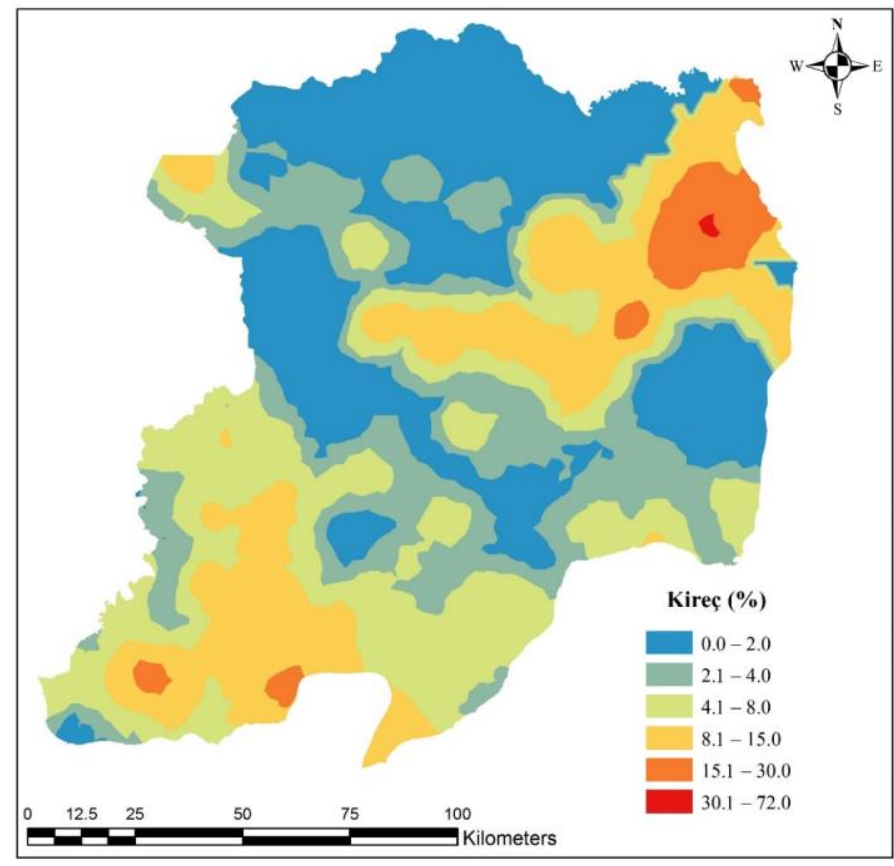

Şekil 6. Trakya topraklarının kireç düzeyi haritası ilave uygulamalara gereksinim gösterdiği gibi demir, çinko ve bor noksanlığı nedeniyle meyvecilik bakımından da sınırlayıcı etki yapabilmektedir. 
Çizelge 4. Trakya topraklarının kireç sınıflarına göre dağılımı (\%)

\begin{tabular}{lllcc}
\hline & Değeri & Sınıfi & Örnek Sayısı & Dağılımı (\%) \\
\hline \multirow{4}{*}{ \% Kireç } & $0-2$ & Kireçsiz, çok az kireçli & 1064 & 56 \\
& $2-4$ & Az kireçli & 277 & 14 \\
& $4-8$ & Orta kireçli & 235 & 12 \\
& $8-15$ & Kireçli & 156 & 8 \\
& $15-30$ & Cok kireçli & 129 & 7 \\
& $>30$ & Marn-kireç toprağı & 47 & 3 \\
\hline
\end{tabular}

\section{Trakya Yöresi Topraklarının Organik Madde Durumu}

Trakya'daki tarım topraklarının, toprak organik madde miktarını Çizelge 5 ve Şekil 7' de incelediğimizde; ortalama olarak \% 80'den fazlasının çok az ve az organik madde içerdiği görülmektedir. Şekil 7'deki harita incelendiğinde, orta düzeyde organik madde içeren topraklar bile büyük oranda ormanlık alanlarda bulunmaktadır. Trakya Yöresindeki tarım arazilerinde organik madde düzeyinin yetersiz olmasının temel nedeni; uzun süredir her yıl toprak işleme ve ekim yapılması, bir dönem anızın yakılması, organik madde miktarını artıracak çiftlik gübresi v.b. uygulamaların yetersizliği, yaz aylarındaki toprak işlemeli ve erozyon sayılabilir. Toprağın organik madde düzeyini artırabilmek için yapılacak uygulamalar zor, zahmetli ve bazen devamlı uygulamalardan oluşmaktadır. Bunlar; belirli aralıklarla (5-10 yılda bir) çiftlik gübresi uygulaması, yeşil gübreleme, kompost ve biyogaz gübrelerinin verilmesi, bitki artıklı ve minimum toprak işlemeli tarım yapılması sayılabilir. Günümüz tüketici toplum felsefesi ile bunları sürdürülebilir hale getirmek bir hayli zor gözükmektedir.

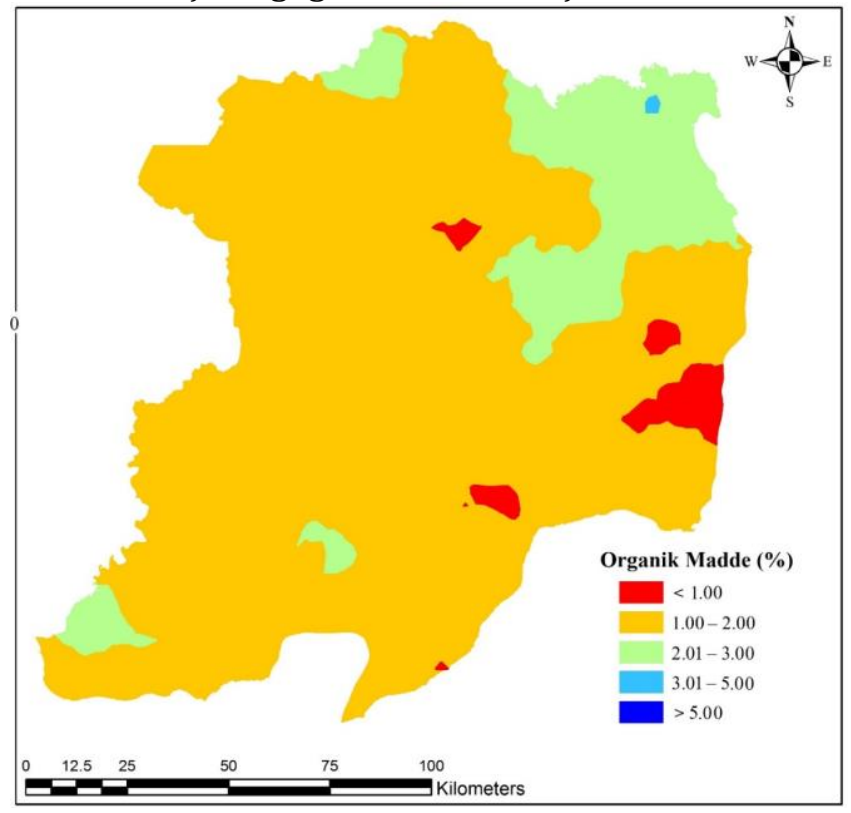

Şekil 7. Trakya topraklarının organik madde kapsamı haritası

Çizelge 5. Trakya topraklarının organik madde kapsamına göre dă̆llımı (\%)

\begin{tabular}{llccc}
\hline & Değeri & Sinıfı & Örnek Sayısı & Dağılımı (\%) \\
\hline \multirow{3}{*}{$0 . \mathrm{M}, \%$} & $<1.00$ & Çok Az & 441 & 23 \\
& $1.00-2.00$ & $\mathrm{Az}$ & 1141 & 60 \\
& $2.01-3.00$ & Orta & 277 & 14 \\
& $3.01-5.00$ & Zengin & 51 & 3 \\
& $>5.0$ & Çok zengin & 2 & 0 \\
\hline
\end{tabular}

\section{Trakya Topraklarının Yarayışlı Fosfor Durumu}

Trakya Yöresi tarım topraklarının yarayışlı fosfor içerikleri incelendiğinde, çok yüksek ve yüksek sınıfına giren fosfor miktarları toplamı \% 50'den fazla olduğu görülmektedir. Bu sonuçlar 1980’lerin başında bu illerimizde yürütülen 'Verimlilik Envanter Çalışması' sonuçları ile karşılaştırıldığında, yüksek ve çok yüksek miktarda fosfor içeren alanların oranının yakın olduğu belirlenmiştir. Trakya'da çeltik büyük oranda Edirne'de ekilmekte ve çeltik tarımında 20-20-0 gibi kompoze gübreler ekim esnasında yoğun olarak kullanılmaktadır. Fosforun topraktan az yıkanması, fazla gübre kullanımından dolayı, bu ilimizin bulunduğu batı kesimlerde fosfor miktarının biraz daha fazla olduğunu göstermektedir. Fosfor bakımından yetersiz ve çok yetersiz alanların yaklaşık \% 20 kadar olması, tarım dışı alanlarda da organik maddenin yüksek oluşundan kaynaklanabilir.

Çizelge 6. Trakya topraklarının yarayıșlı fosfor içerikleri dağılımı

\begin{tabular}{llccc}
\hline & Değeri & Sınıfi & Örnek Sayısı & Dağılımı (\%) \\
\hline & $<0-5.0$ & Çok yetersiz & 66 & 3 \\
Fosfor & $5.1-12.0$ & Yetersiz & 308 & 16 \\
$\left(\mathrm{P}, \mathrm{mg} \mathrm{kg}^{-1}\right)$ & $12.1-25.0$ & Orta & 528 & 28 \\
& $25.1-50.0$ & Yüksek & 626 & 33 \\
& $>50$ & Çok yüksek & 384 & 20 \\
\hline
\end{tabular}




\section{Trakya Topraklarının Ekstrakte Edilebilir Potasyum Kapsamları}

Çizelge 7'nin ve Şekil 9'un incelenmesinden de anlaşılacağı üzere, Trakya topraklarının potasyum bakımından yaklaşık \% 14'ü az, \%14'ü çok az, \%12'si yeterli, \%38'u yüksek ve \%21'i çok yüksek sınıfında yer almıştır. Yöre topraklarının, az ve orta sınıflarda potasyum içermesinin ana nedeni; asit reaksiyonlu, kumlu ve tınlı toprakların bulunmasından kaynaklandığı düşünülmektedir. Zira Şekil 9'daki ekstrakte edilebilir potasyum haritasında potasyumun yetersiz olduğu alanlar, Şekil 3'deki pH haritası ile karşılaştırıldığında topraktaki pH seviyesinin düşük olduğu alanlarla hemen hemen çakıștığı görülecektir. Yüksek ve çok yüksek miktarda potasyum bulunmasının sebebi ise; yörede fazla miktarda kil içeren vertisol toprakların geniş alanlar kapsamasından kaynaklanmaktadır.

Çizelge 7. Trakya topraklarının ekstrakte edilebilir potasyum içerikleri dağılımı

\begin{tabular}{|c|c|c|c|c|}
\hline & Değeri & Sinifi & Örnek Sayısı & Dağılımı (\%) \\
\hline & $<80$ & $\mathrm{Az}$ & 273 & 14 \\
\hline Potasyum & $80-120$ & Orta & 268 & 14 \\
\hline \multirow[t]{3}{*}{$\left(\mathrm{K}, \mathrm{mg} \mathrm{kg}^{-1}\right)$} & $121-160$ & Yeterli & 235 & 12 \\
\hline & $161-320$ & Yüksek & 738 & 39 \\
\hline & $>320$ & Çok yüksek & 398 & 21 \\
\hline
\end{tabular}

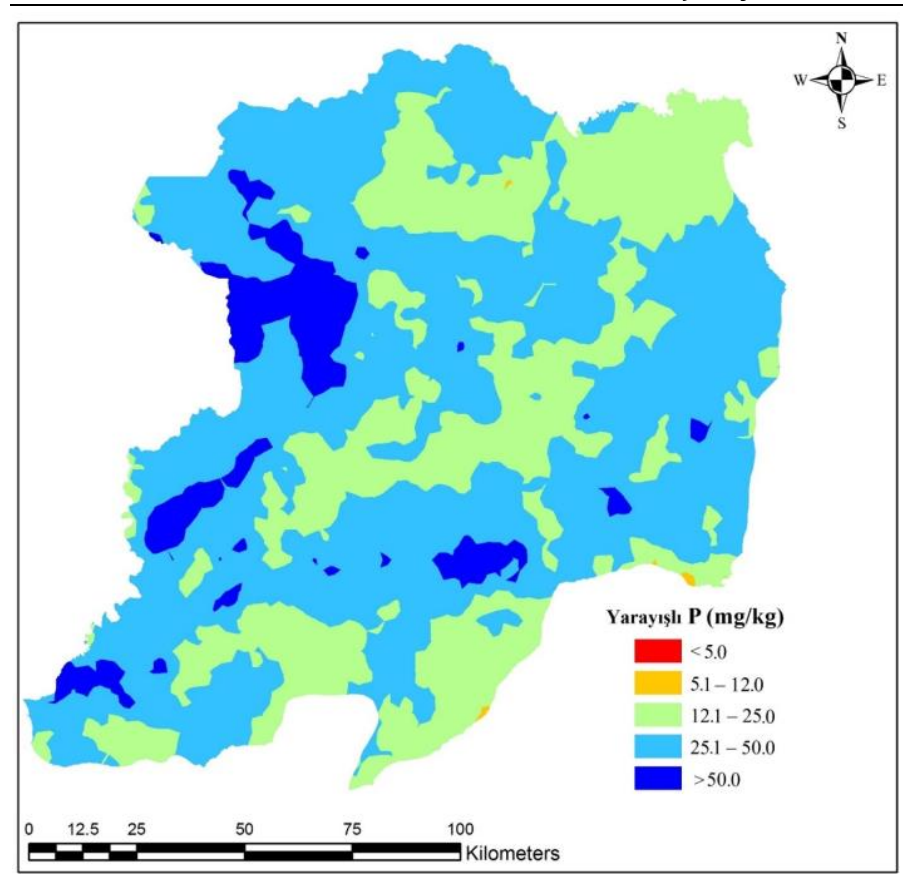

Şekil 8. Trakya topraklarının yarayışlı fosfor dağılımı haritası

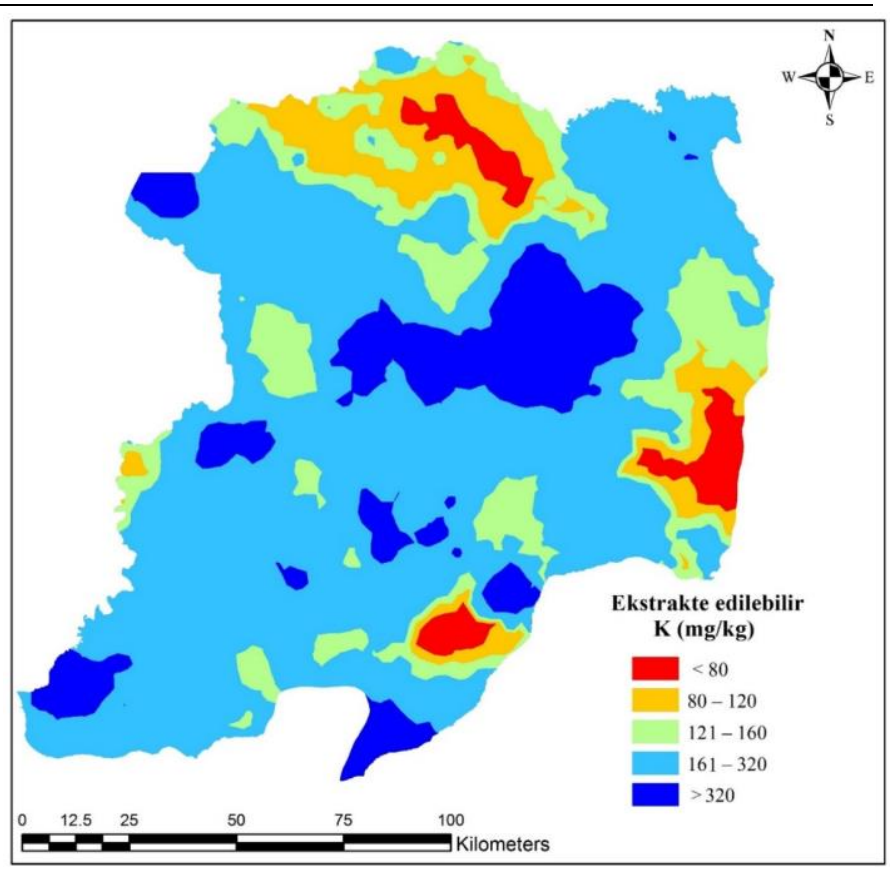

Şekil 9. Trakya topraklarının ekstrakte edilebilir potasyum içeriği haritası

\section{Trakya Topraklarının Ekstrakte Edilebilir Magnezyum Kapsamları}

$\mathrm{Bu}$ çalışma kapsamında elde edilen Trakya topraklarının magnezyum durumunu gösteren Çizelge 8'in incelenmesinden de anlaşılacağı üzere, ekstrakte edilebilir magnezyum bakımından \%4'ü çok yetersiz, \%8'i yetersiz, \%65'i orta, \%21'i yüksek ve \%2'si çok yüksek sınıfında yer almaktadır. Çok yetersiz ve yetersiz sınıfında magnezyum içeren toprakların yörede mevcudiyeti volkanik ana materyalden oluşan asit reaksiyonlu toprakların bulunması ve bu toprakların yeterince kireçlenmemesine bağlıdır. Üzerinde bitkisel üretim yapılan bu alanlarda bazı bölgelerde sulamanın da yapılması ile hem yıkanma ve hem de ürün tarafından kaldırılan magnezyum miktarı artmıştır. Magnezyumun yöre tarım topraklarında yüksek ve çok yüksek miktarlarda bulunmasının nedenini ise, toprakların az bir kısmının kireçli ve bir miktar da alüviyal ana materyalden oluşmasından kaynaklandığı düşünülmektedir (Şekil 10).

Çizelge 8. Trakya topraklarının ekstrakte edilebilir magnezyum miktarı dağılımı

\begin{tabular}{lcccc}
\hline & Değeri & Sınıfı & Örnek Sayısı & Dağılımı (\%) \\
\hline & $0-50$ & Cok yetersiz & 79 & 4 \\
Magnezyum & $51-100$ & Yetersiz & 145 & 8 \\
$\left(\mathrm{Mg}, \mathrm{mg} \mathrm{kg}^{-1}\right)$ & $101-500$ & Orta & 1240 & 65 \\
& $501-1000$ & Yüksek & 408 & 21 \\
& $>1000$ & Çok yüksek & 40 & 2 \\
\hline
\end{tabular}




\section{Trakya Topraklarının Ekstrakte Edilebilir Demir Kapsamları}

Trakya Yöresi tarım topraklarının DTPA ile ekstrakte edilebilir demir içerikleri Çizelge 9‘dan incelendiğinde yetersiz sınıfına giren demir içeriğine sahip toprakların oranının \% 8 olduğu görülmektedir. Taşova ve Akın (2013), Marmara Bölgesi topraklarının DTPA ile ekstrakte edilebilir Fe miktarının, \%86,7 oranında yeterli olduğunu belirtmişlerdir. Zbiral (2016), yaptığı araștırmada son güncel çalışmaları dikkate alarak DTPA ile ekstrakte edilebilir mikroelement alt limit değeri olarak Lindsay ve Norvel (1979)'dan farklı değerler vermiştir. Demir için yeterlilik alt sınır değeri olarak $8 \mathrm{mg} / \mathrm{kg}$ değeri kabul edilmiştir. Bu çalışmada, Çizelge 9'da bu değere göre sınıflandırmalar yapılarak Şekil 10'daki harita oluşturulmuștur. Demir besin elementi toprak ana materyalinde bol miktarda bulunan bir mikro besin elementidir. Yöredeki asit reaksiyonlu topraklarda yüksek miktarlara çlkabilmekte, kireç içeriği yüksek topraklarda yetersiz düzeylere düşebilmektedir. Demir noksanlığı bazı meyve türlerinde (șeftali, elma, ayva) belirgin șekilde noksanlık belirtileri gösterse de, eksikliği giderilmez ise yörede yaygın olarak ekilen ürünlerde de gizli açlık şeklinde noksanlı̆̆g görülebilir.

Çizelge 9. Trakya topraklarının ekstrakte edilebilir demir miktarı dağılımı

\begin{tabular}{lllcc}
\hline & Değeri & Sınıfı & Örnek Sayısı & Dağılımı (\%) \\
\hline & $<8,0$ & Az & 162 & 8 \\
Demir $\left(\mathrm{Fe}, \mathrm{mg} \mathrm{kg}^{-1}\right)$ & $>8,0$ & Yüksek & 1562 & 82 \\
\hline
\end{tabular}

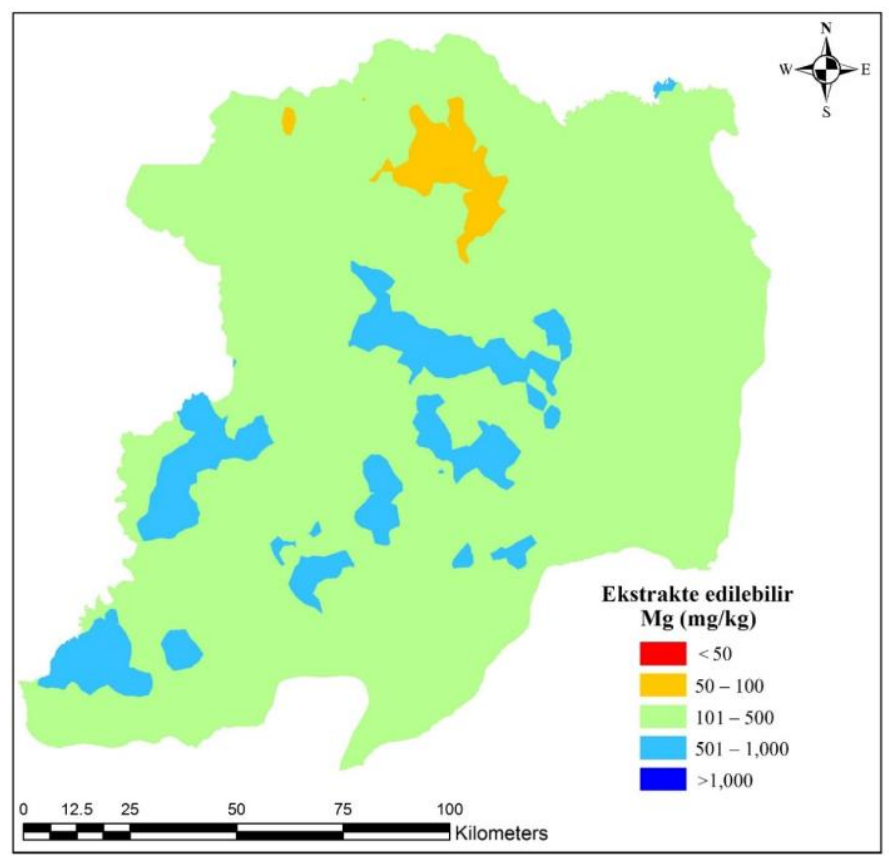

Şekil 10. Trakya topraklarının ekstrakte edilebilir magnezyum düzeyi haritası.

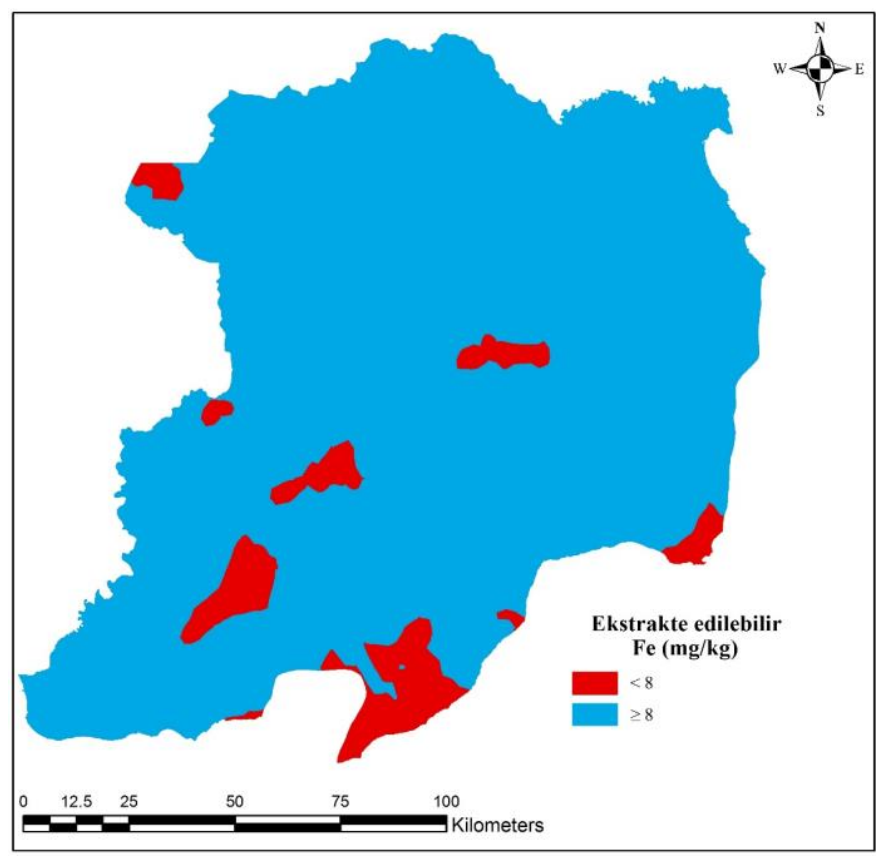

Şekil 11. Trakya topraklarının ekstrakte edilebilir demir düzeyi haritası.

\section{Sonuç}

Trakya topraklarının veri tabanının oluşturulması ve bazı toprak özelliklerinin oluşturulması çalışmasında aşağıdaki sonuçlara varılabilir.

1. Yöre toprakları bünye bakımından, oluştukları ana materyale bağlı olarak farklı karakterlere sahiptir. Toprakların yaklaşık, 1/3'ünün hafif, 1/5'inin orta ve 2/5'inin ağır bünyeli olduğu söylenebilir.

2. Toprak reaksiyonu bakımından, yaklaşık $2 / 5^{\prime}$ inin asit, $1 / 5$ 'inin nötr ve $2 / 5$ 'inin ise alkalin reaksiyonlu topraklardan oluştuğu söylenebilir. Toprak reaksiyonu $(\mathrm{pH})$ bakımından, yörede yaygın olarak tarımı yapılan buğday ve ayçiçeği bitkileri için, olumsuz toprak koşullarına neden olan toprak asitliğinin giderilmesi için gerekli tarımsal uygulamaların yapılması üretimi artırmak bakımından yararlı olacaktır.

3. Yöre topraklarında tuzluluk önemli bir sorun gibi gözükmemektedir. Zira, tuz bakımından toprakların 3/4'ü tuzsuz ve diğer kısmı çok hafif ve hafif tuzlu durumdadır. Çok hafif ve hafif tuzlu alanlarda çeltik tarımı sorunsuz bir şekilde sürdürülmektedir.

4. Yöre toprakları kireç bakımından; 1/2'si kireçsiz ve çok az kireçli, $1 / 7$ az kireçli, 1/5'i orta kireçli ve kireçli ve $1 / 10$ 'u ise çok kireçli sayılabilir. Kireçsiz ve çok az kireçli olan alanların bir kısmında asit 
reaksiyon nedeniyle kireçlemeye ihtiyaç duyulmaktadır. Bu da, üreticiye maliyeti nedeniyle yörede yetersiz oranda yapılmaktadır. Çok kireçli alanlarda ise, özellikle meyvecilik yapıldığı durumlarda sorunlar ortaya çıkmaktadır.

5. Organik madde bakımından $1 / 5^{\prime} \mathrm{i}$ çok az, 3/5'i az, 1/5'i ise orta ve zengin durumdadır. Yöre topraklarında organik madde düzeyinin yetersizliğinden kaynaklanan fiziksel toprak özellikleriyle ilgili sorunlar belirmeye başlamıştır. Özellikle yazlık ürünlerde ekim sonrası kabuk oluşumu ve bitki çıkışının engellenmesi sonucu önemli maddi kayıplar meydana gelmektedir. Organik madde miktarını artıracak yeşil gübreleme, organik gübre ve materyallerin uygulanmasında yarar görülmektedir.

6. Yöre topraklarında, yarayışlı fosfor miktarı, 1/5'inde yetersiz ve çok yetersiz, 1/4'ü orta, 3/10'unda yüksek ve $1 / 5$ 'i çok yüksek olarak belirlenmiştir. Yöredeki tarım alanlarında, gübrelemeden kaynaklanan fosfor birikim alanları mevcuttur. Üreticilerimizi toprak analizine yaptırmaya yönlendirerek, gereksiz fosforlu gübre kullanımından uzak tutmalıyız.

7. Trakya'da tarım yapılan topraklar ekstrakte edilebilir potasyum bakımından, $1 / 10$ 'u yetersiz ve çok yetersiz, $2 / 5$ 'i orta ve zengin ve $3 / 5$ 'i zengin ve çok zengin sınıfında yer almıştır. Yöre topraklarında potasyum noksanlığı az görülse de, oluşturacağı etki bakımından ihmal edilmemelidir. Potasyum bir makro besin elementidir ve bitkiler tarafından bol miktarda kullanılmaktadır. Bazı kompoze gübrelerin yapısında bulunsa da (15-15-15 gibi), sadece potasyum içeren potasyumlu gübrelerin (potasyum sülfat gibi) de bayilerde bulunmasında ve ulaşılabilir olmasında yarar vardır.

8. Ekstrakte edilebilir magnezyum bakımından ise; $1 / 10^{\prime}$ u yetersiz ve çok yetersiz, $3 / 5$ 'i orta ve $2 / 5$ i ise yüksek ve çok yüksek düzeylerde yöre topraklarında belirlenmiştir. Yörede eksikliği, büyük ölçüde asit reaksiyonlu topraklarda görülmektedir. Yetersiz alanlarda eksikliğin giderilmesi tarımsal üretim bakımından yararlı olacaktır.

9. Trakya Yöresi tarım topraklarının DTPA ile ekstrakte edilebilir demir içerikleri incelendiğinde, yetersiz sınıfına giren demir içeriğine sahip toprakların oranının \% 8 olduğu görülmektedir. Bu oran düşük de olsa, toprak analiz ile demir noksanlığı belirlenen alanlara bu noksanlığı giderecek topraktan ve yapraktan gerekli gübreleme uygulamaları yapılmalıdır. Hatta bu alanda, yörenin ana münavebe ürünleri olan buğday ve ayçiçeği gelişmesine ve verimine etkileri araştırma konusu üzerinde araştırmalar yapılabilir.

Sonuç olarak; yörede çok sayıda toprak analiz laboratuvarının bulunması, bu laboratuvarların gelişmişlik, altyapı düzeyi, yeterli eğitim, araştırma, yönetim ve uygulamaya da yansıtılarak, tarım alanlarında toprak özelliklerinin ana materyale bağlı olmayan (bünye, kireç gibi) tarımsal üretimde sınırlandırıcı faktör olan diğer özelliklerini ( $\mathrm{pH}$, organik madde fosfor, potasyum, magnezyum, demir) iyileştirebiliriz.

\section{Kaynaklar}

Anonim, 1984a. Edirne ili verimlilik envanteri ve gübre ihtiyaç raporu. T.C. Tarım Orman ve Köyişleri Bakanlığı Topraksu Genel Müdürlüğü Yayınları, TOVEP Yayın No: 14, Genel Yayın No: 742, Ankara.

Anonim, 1984b. Kırklareli ili verimlilik envanteri ve gübre ihtiyaç raporu. T.C. Tarım Orman ve Köyişleri Bakanlığı Topraksu Genel Müdürlügü Yayınları, TOVEP Yayın No: 20, Genel Yayın No: 752, Ankara.

Anonim, 1984c. Tekirdağ ili verimlilik envanteri ve gübre ihtiyaç raporu. T.C. Tarım Orman ve Köyişleri Bakanlığı Topraksu Genel Müdürlügü Yayınları, TOVEP Yayın No: 13, Genel Yayın No: 741, Ankara.

Bahar E, 2014, Marmara Bölgesi Trakya Bölümü topraklarının kuraklık hassasiyet analizi. Çanakkale Onsekiz Mart Üniversitesi Fen Bilimleri Enstitüsü. Doktora Tezi. Basılmamış.

Bouyoucos GJ, 1951. A recalibration of the hydrometer method for making mechanical analysis of soil. Agronomy Journal 43: 434-438

Eyüpoğlu F, Kurucu N, Talaz S, 1998. Türkiye topraklarının bitkiye yarayışlı bazı mikro elementler (Fe, Cu, Zn, Mn) bakımından genel durumu, KHGM. Toprak ve Gübre Araştırma Enstitüsü Müd. Yayınları.

Lindsay WL, Norvell WA, 1978. Development of a DTPA soil test for zinc, iron, manganese and copper. Soil Science Society America Journal 42: 421-428.

Methods of Soil Analysis-Part II, 1982. Chemical and Microbiological Properties, 2nd ed. ASA-SSSA, Agronomy Nomograph No:9, Madison, WI.

Richards LA, 1954. Diagnosis and improvement of saline and alkali soils. United States Department of Agriculture Handbook, s:60-94.

Taşova H, Akın A, 2013. Marmara Bölgesi topraklarının bitki besin maddesi kapsamlarının belirlenmesi, veri tabanının oluşturulması ve haritalanması. 6. Ulusal Bitki Besleme ve Gübre Kongresi. 03-07 Haziran 2013 Nevşehir, s:279281.

Zbíral J, 2016. Determination of plant-available micronutrients by the Mehlich3 soil extractant - a proposal of critical values. Plant Soil and Environment 62(11): 527-531. 